\title{
Application of a lower-fidelity surrogate hydraulic model for historic flood reconstruction
}

\author{
A. Bomers ${ }^{a, *}$, R. M. J. Schielen ${ }^{\mathrm{a}, \mathrm{b}}$, S. J. M. H. Hulscher ${ }^{\mathrm{a}}$ \\ ${ }^{a}$ University of Twente, Dienstweg 1, Enschede, The Netherlands \\ ${ }^{b}$ Ministry of Infrastructure and Water Management-Rijkswaterstaat, Arnhem, The Netherlands
}

\begin{abstract}
Two dimensional hydraulic models are useful to reconstruct maximum discharges and uncertainties of historic flood events. Since many model runs are needed to include the effects of uncertain input parameters, a sophisticated 2D model is not applicable due to computational time. Therefore, this papers studies whether a lower-fidelity model can be used instead. The presented methodological framework shows that a 1D-2D coupled model is capable of simulating maximum discharges with high accuracy in only a fraction of the calculation time needed for the high-fidelity model. Therefore, the lower-fidelity model is used to perform the sensitivity analysis. Multiple Linear Regression analysis and the computation of the Sobol' indices are used to apportion the model output variance to the most influential input parameters. We used the 1926 flood of the Rhine river as a case study and found that the roughness of grassland areas was by far the most influential parameter.
\end{abstract}

Keywords: lower-fidelity model, Sensitivity analysis, Uncertainty, Historic flood reconstruction

\section{Introduction}

Currently, the Dutch water policy is changing from a probability exceedance approach towards a risk based approach. In addition to the probabil-

5 ities of floods due to multiple failure mechanisms, this new approach also considers the consequences of a flood. The risk based approach results in a significant increase in the safety levels in areas where the consequences are large (Dutch Ministry of Infrastructure and the Environment and Ministry of Economic Affairs, 2014). A maximum return period of 1,250 years was defined for the river areas in the probability exceedance approach, while the risk based approach has maximum return periods of 15 100,000 years. The prediction of design discharges corresponding to such rare events is highly uncertain. These predictions are most often based on relatively short data sets of measured weather conditions or discharges. Therefore, the data set does by a very low frequency (Barriendos et al., 2003).

The confidence interval of large design discharges can be reduced by extending the data set of measured discharges with historical and paleo data 25 of extreme flood events (Neppel et al., 2010, Sheffer et al. 2003). Many studies have reconstructed historic floods to expand the data set of measured discharges (e.g Herget et al. (2015); Herget and Meurs (2010); Llasat et al. (2005); Neppel et al. 30 (2010); O'Connell et al. (2002); Sheffer et al. (2003); Toonen et al. (2015); Zhou et al. (2002)). Herget et al. (2015) and Herget and Meurs (2010) reconstructed historic discharges in the city of Cologne, Germany, based on historical documents. They predicted mean flow velocities at the time of the historic flood events with the use of a reconstructed river channel and floodplain bathymetry. The empirical Manning's equation was used to estimate the historic discharges of a specific cross section near the city of Cologne. Neppel et al. (2010) used hy-

\footnotetext{
${ }^{*}$ Corresponding author

Email address: a.bomers@utwente.nl (A. Bomers)
} 
draulic modelling of a reach of about two kilometres length to account for geomorphological changes. With this model, present and historic rating curves were constructed and applied to determine flood discharge series (Neppel et al. 2010). O'Connell et al. (2002) used Bayesian statistics to create paleohydrologic bound data for flood frequency analysis. Paleohydrologic bound data represent stages 100 and discharges that have not been exceeded since

50 the geomorphic surface stabilized (O'Connell et al. 2002). These bounds are not actual floods, but are limits on flood stage over a measured time interval. O'Connell et al. (2002) found that paleohydrologic 105 bounds reduce the uncertainties of the flood distri-

55 bution curve by placing large observed discharges in their proper long-term contexts. Toonen et al. (2015) reconstructed Lower Rhine historical flood magnitudes of the last 450 years with the use of 110 grain-size measurements of flood deposits at two 60 separate research locations. They made use of linear regression plots between various grain-size descriptors and measured discharges to determine the discharges of the historic events.

Above mentioned studies tried to gain insight in 65 the maximum discharge of a historic flood. However, none of these studies used hydraulic models to describe maximum discharges and its uncertainties along a long stretch of a river including possible bi- 120 furcations during the historic events. However, the 70 use of hydraulic models may decrease the confidence intervals of the predicted maximum discharges of the reconstructed flood events. Furthermore, hydraulic models provide insight in the flow patterns 125 and inundation extents of the historic events. For 75 these reasons, hydraulic models will be used for historic flood reconstructions in this study.

Hydraulic models require a reconstruction of the historical geometry as input data. In addition, 130 they require proper boundary conditions to determine the flood wave propagation along the model domain. However, the data available to reconstruct historic flood events is limited. Measured discharges or water levels are generally not available. ${ }_{135}$ Also, the geometry of the river, its floodplains and 85 the hinterland may be uncertain. This uncertainty is reflected in the uncertainty of the model input parameters, affecting the maximum discharges during a flood event. For this reason, a sensitivity anal- 14 ysis on the maximum discharge will be necessary

90 to find the input parameter that mostly influences the model output. This analysis will also gain insight in the confidence interval of the reconstructed maximum discharge. This insight provides us with useful information for other historical geometry reconstructions, since parameter prioritization can be used during the reconstruction.

Commonly, sophisticated two dimensional (2D) hydraulic models (in this context also called a highfidelity model, see Section 2.1) are used for hydraulic modelling. This is because they are capable of describing maximum discharges, flood extent and inundation patterns with high accuracy. However, they have the disadvantage that a single run of a discharge wave usually takes at least several hours. Since sensitivity analyses require many model runs, $2 \mathrm{D}$ models are not suitable for this purpose. To reduce computational time, a surrogate model will be set up. A lower-fidelity model is developed since this type of surrogate model does not lose many physical processes of the original system. Therefore, the objective of this paper is to study whether a lower-fidelity hydraulic model can be used for historic flood reconstructions.

Lower-fidelity surrogate modelling has just recently started to gain popularity in the water resources literature (Razavi et al., 2012b). The modelling approach has been applied to groundwater models to reduce model complexity for optimization and calibration purposes (e.g. Maschler and Savic (1999); McPhee and Yeh (2008); Ulanicki et al. (1996)). It has also been applied in combination with the Monte Carlo framework for uncertainty analysis (e.g. Efendiev et al. (2005); Keating et al. (2010)). However, almost no studies have applied a lower-fidelity surrogate model for hydraulic modelling purposes. These models may have great benefits in this field since computational time can be reduced significantly while model accuracy remains sufficient. For an elaborated review on surrogate models in environmental modelling, see Razavi et al. (2012b).

Razavi et al. (2012b) argue that the response patterns of a lower-fidelity model and of a sophisticated 2D model can differ, even if both models are based on the same input data. Therefore, the results of a $2 \mathrm{D}$ model will be used for validation purposes. If the model output of the lower-fidelity model is close to those predicted by the $2 \mathrm{D}$ model, the lower-fidelity model is capable of accurately simulating the system behaviour. Hence, the lowerfidelity model can be used to perform the sensitivity analysis. For future work, the lower-fidelity model can be treated as a high-fidelity model. The proposed method (Fig. 1) will answer the following 
three research questions:

- Under what circumstances can a lower-fidelity model be used to simulate a historic flood event?

- How can we apply a lower-fidelity model to compute the maximum discharge and its uncertainty of a historic flood event?

- Which uncertain input parameter contributes 200 most to the uncertainty of the maximum discharge?

We apply the proposed method to the 1926 flood of the Rhine river. Sufficient information is available to reconstruct the 1926 geometry. In addition, water levels were measured during the event. Due to high rainfall intensities in the Lower Rhine catchment area and increased amount of melting water as a result of relatively high temperatures in Switzerland, the 1926 discharge resulted in the highest discharge at Lobith since measurements have been performed.

The outline of the paper is as follows. Firstly, the high-fidelity (2D) model is described in Section 2.1, after which the surrogate model is set up (Section 2.2). Then, the 1926 case is provided and the methodology of the sensitivity analysis is given in Section 2.3 and Section 3, respectively. Subsequently, the calibration results of the high-fidelity model (Section 4.1) and the validation results of the surrogate model (Section 4.2) are provided. Finally, the results of the sensitivity analysis are elaborated on Section 4.3. The paper ends with a discussion and the main conclusions in Section 5 and 6 , respectively.

\section{Methodology of surrogate modelling}

In this section, the model structure of a fully $2 \mathrm{D}$ model is explained. This model represents the highfidelity model in this study and is used to validate the lower-fidelity model. Thereafter, the $2 \mathrm{D}$ model is simplified to decrease computational time significantly. Many methods exist to simplify a highfidelity model to create a lower-fidelity model. Why a 1D-2D coupled model is used in this study, is explained in Section 2.2

\subsection{High-fidelity model}

Most often, 2D flood models are used to get insight in the consequences of high discharge stages.
With 2D models, it is possible to get a high detailed and accurate representation of potential floods along a river. Up till now, the 2D Shallow Water equations are usually solved with the 5 use of a curvilinear grid (Fig. 2). The curvilinear grid cells are aligned with the flow direction since flow variations in the channel length direction are often smaller than those in channel cross direction (Kernkamp et al., 2011). This is convenient in terms of computational time. However, a curvilinear grid has several disadvantages. Firstly, grid lines are focused and sometimes even intersect in sharp inner bends (Fig. 2, where the dashed lines indicate the focused grid lines). The focused grid lines result in unnecessarily small grid cells if the model domain is extended in the inner bend. These small grid cells significantly increase computational time. Additionally, the grid will lead to a staircase representation along closed boundaries since the grid is not capable of following the smooth boundaries of the model domain (Kernkamp et al. 2011). Finally, the grid is restrictive in representing a natural river system with different geometric features such as main channels, junction points and wide floodplains due to the curvilinear shape of the grid cells (Lai, 2010).

Due to the above mentioned shortcomings of a curvilinear grid, a hybrid grid is used to solve the 2D Shallow Water equations in this study (Fig. 2). 220 The summer bed is discretized by curvilinear grid cells. These cells are aligned with the flow direction. The winter bed is discretized by triangular grid cells such that each triangular grid cell is connected to a single curvilinear grid cell. As a result, a smooth transition exists between the curvilinear and triangular grid cells (Fig. 2). This hybrid grid overcomes the shortcomings of a curvilinear grid. It also reduces the computational time while model accuracy stays sufficient (Bomers et al., 2019). Fig. 2303 shows the hybrid grid and a typical example of model output. The open source software D-Flow Flexible Mesh (FM) is used to set up the 2D model (Deltares, 2016). In each grid cell, parameters such as water level and flow velocity can be computed for every time step. A variable time step is used based on the maximum Courant number. As a result, the model stays stable during the simulation:

$$
C=\frac{u * \Delta t}{\Delta x}
$$

where $u$ represents the velocity magnitude $[\mathrm{m} / \mathrm{s}]$, $\Delta t$ the time step $[\mathrm{s}]$ and $\Delta x$ the grid size in $\mathrm{x}-$ 


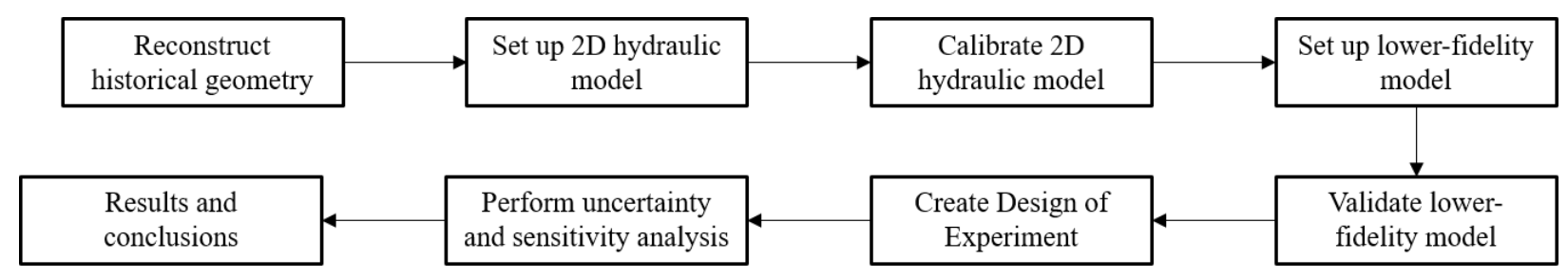

Figure 1: Methodology for historic flood reconstruction

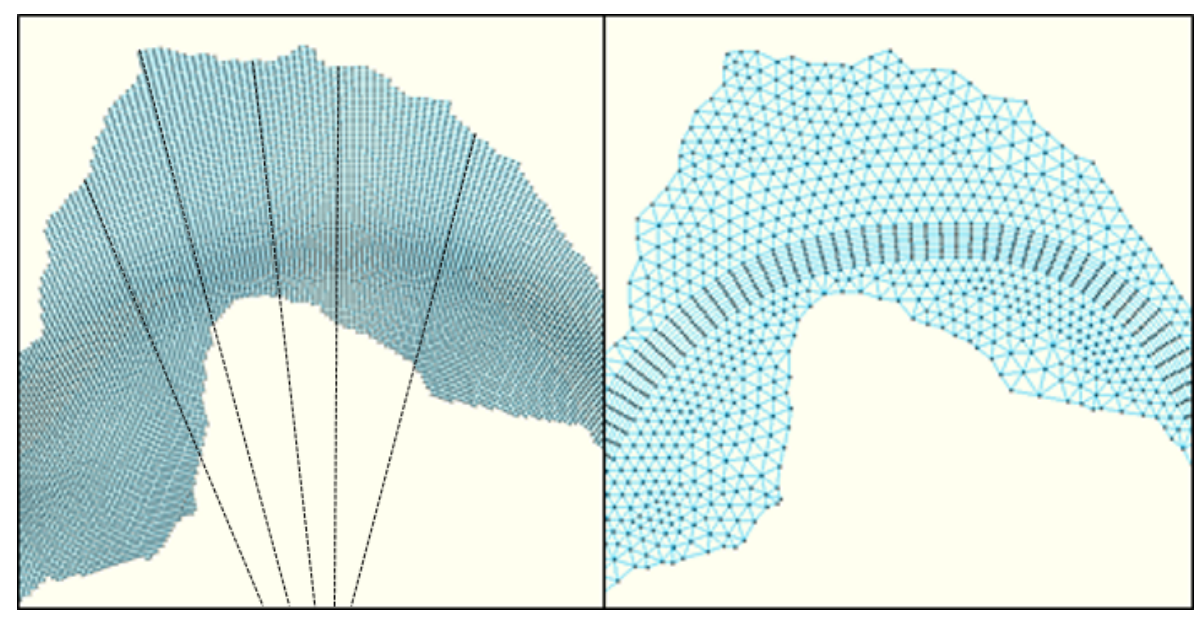

Figure 2: An example of a curvilinear grid in which the dashed lines represent the focused grid lines (left figure) and a hybrid grid (right figure) in a sharp meander bend

rection $[\mathrm{m}]$. A maximum Courant number of 0.95 is used and $\Delta t$ is adapted accordingly.

D-Flow FM allows multiple roughness definitions to be implemented in a single model run, e.g.: a Manning's value, a Nikuradse value or a Van Rijn predictor. In general, the land use classifications, and hence the roughness classes, are based on an 270 input database. A database provided by the Dutch Ministry of Infrastructure and Water Management is used. This database includes multiple roughness definitions that coincide with the land use classification of the studied area.

Calibration of a $2 \mathrm{D}$ grid is required since each $2 \mathrm{D}$ grid has its own numerical friction caused by the resolution of the grid cells (Caviedes-Voullième et al. 2012). A coarser grid results in a somewhat dampened discharge wave. This effect can even become larger than those generated by physical friction (Caviedes-Voullième et al., 2012). During calibration, this numerical grid generated friction will be compensated such that reliable water levels are predicted. Hydraulic model calibration is most ${ }^{285}$ commonly done by changing the roughness of the summer bed until simulated water levels are close to measured water levels (e.g Bomers et al. (2019) and 265 Caviedes-Voullième et al. (2012)). In this study, the same approach was used. The calibration procedure was performed with the use of the open source software OpenDA (http://www.openda.org/). The basic idea of the procedures of OpenDA is to find the set of model parameters which minimizes the cost function measuring the distance between the measured water level and the model prediction (The OpenDA Association, 2016). The Quadratic Cost Function is used in combination with the Sparse 275 DUD (Does not Use Derivate) algorithm. For N calibration parameters (in this study $\mathrm{N}=10$ ), the algorithm requires $(\mathrm{N}+1)$ set of parameter estimates. The cost function, based on the model predictions and measured data, is used to get a new estimate. If the cost function does not produce a better estimate, the Sparse DUD algorithm will search in opposite direction and/or decreases the searching-step until a better estimate is found (The OpenDA Association, 2016). In this study, the calibration procedure is stopped if the average RMSE of each measurement station is smaller than $0.05 \mathrm{~m}$. For more information on the calibration procedure 


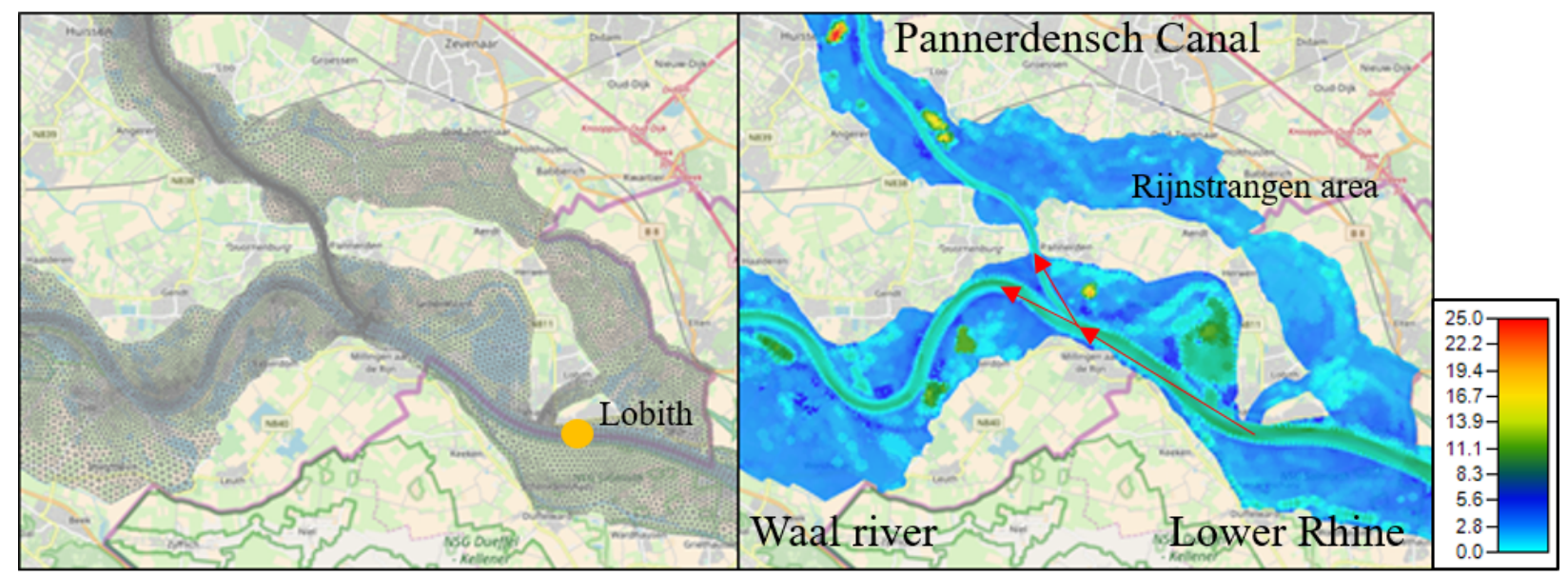

Figure 3: Example of a hybrid grid of a 2D hydraulic model (left figure) and computed water depths as a result of an upstream discharge wave (right figure). The red arrows indicate the flow direction

of OpenDA, see The OpenDA Association (2016).

\subsection{Lower-fidelity physically based surrogate model}

A hybrid 2D grid reduces computational time compared to a curvilinear grid. However, the computational time of simulating a discharge wave of approximately three weeks is still in the order of many hours. For sensitivity analysis purposes, many model runs (120 in this study) have to be performed. Therefore, a model with a computational time in the order of minutes is desirable. For this reason, a surrogate model based on the high ${ }_{330}$ detailed 2D model is developed. This model is explained in more detail in the next sections.

\subsubsection{Types of surrogate modelling}

Surrogate models approximate the response pattern of a high detailed and computationally intensive simulation model (Razavi et al. 2012a). Many methods to construct a surrogate model exist in literature. These methods can be divided into two classes, namely (1) response surface surrogates which are statistical or empirical data-driven models emulating the original system, and (2) lowerfidelity physically based surrogates which are simplified models of the high detailed model (Razavi et al., 2012b).

Regardless of the type of response surface surrogates, usually three steps are involved (Simpson et al. 2001): (1) choosing a design of experiment for generating the training data, (2) choosing a statistical or empirical data-driven model (e.g. Ar- ${ }_{350}$ tificial Neural Network, Support Vector Machine,
Gaussian Progress Regression model) to represent o the data, and (3) fitting the surrogate model to the training data. Response surface surrogates are commonly used for automatic model calibration (Razavi et al., 2012b). To fit the response surface surrogate, training data is required. Therefore, the high-fidelity model still needs to be run multiple times. Because of the relatively long simulation time of this model, the methods based on response surface surrogates are not desirable. For this reason, the high-fidelity model is simplified using method (2): creating a lower-fidelity physically based surrogate model. Lower-fidelity surrogate models are set up based on the original input data. Therefore, for lower-fidelity modelling, only a single run with the high-fidelity model is required for validation purposes. Moreover, lowerfidelity models are more reliable in predicting the output of the high-fidelity model in unexplored regions of the input space since they predict model output based on the original input data Razavi et al. 2012b). Different methods exist to simplify the original model, e.g. larger grid size, less strict numerical convergence tolerances or, ignoring or approximation physics of the original system (Razavi et al. 2012b). Those methods were not sufficient to model significantly. Therefore, it was decided to approximate several physical processes of the original system by: (1) lowering the dimension of the model, (2) increasing the computational time step, and (3) simplifying the Shallow Water equations of 


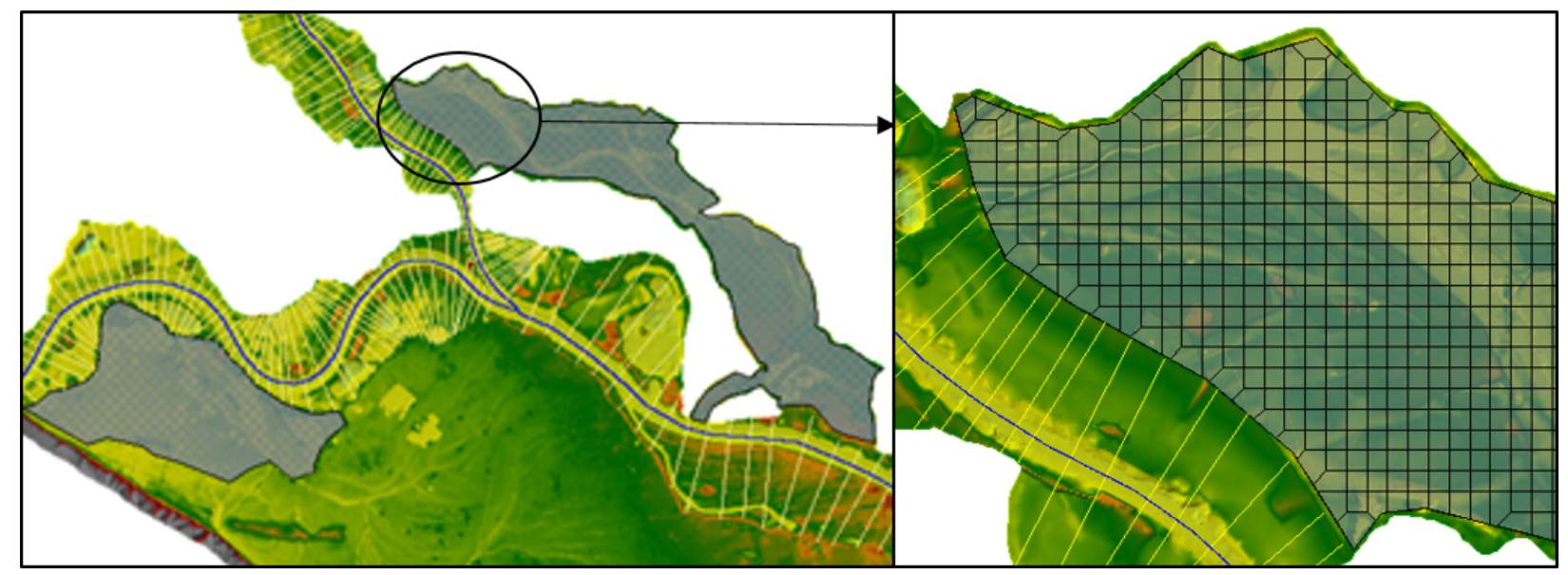

Figure 4: Set-up of the 1D-2D coupled model (left figure) in which the yellow lines indicate the 1D profiles and the grey areas the $2 \mathrm{D}$ embanked areas, and a close-up of the 2D grid which clearly shows the flexible grid shapes along the boundaries of the model domain (right figure)

the fully 2D model. The set-up of the lower-fidelity model is explained in the next section.

\subsubsection{Set-up lower-fidelity model}

The surrogate model developed represents a 1Dcoupled model to combine the advantages of both a fully $2 \mathrm{D}$ and a fully $1 \mathrm{D}$ model. $1 \mathrm{D}$ profiles give an accurate representation of flood wave propagation in case of in-channel flows (Tayefi et al. 2007). Additionally, the computational cost is relatively low compared to a fully $2 \mathrm{D}$ model. How ever, the use of 1D profiles may be insufficient for more complex flow patterns because of the simplified assumptions in the computational schemes. In 395 the embanked areas rapidly changes in flow velocity direction may occur. For this reason, 1D profiles are solely used for the flow between the winter dikes, i.e. the summer bed and winter bed. The 1D profiles are coupled with $2 \mathrm{D}$ embanked areas that 400 are possible to inundate. The embanked areas refer 370 to the areas protected by dikes and are therefore not part of the river system. The embanked areas are discretized with a rectangular 2D grid. Flexible grid shapes are used along the boundaries of the 40 model domain such that the 2D grid cells follow these boundaries. The flexible grid cells along the boundaries can have a maximum of eight boundary edges. Fig. 4 shows an example in which the 1D profiles of the rivers and the 2D embanked areas are ${ }_{410}$ given by yellow lines and grey areas, respectively. A close-up of the 2D grid and its flexible grid shapes along the grid boundaries is also provided.
HEC-RAS (v. 5.0.3), developed by the Hydrologic Engineering Centre (HEC) of the US Army Corps of Engineers, is used for the 1D-2D flood modelling. HEC-RAS is well known for its 1D flood modelling applications. Horritt and Bates (2002) even showed that HEC-RAS produces flood extents more accurately than the 2D models of LISFLOODFP and TELEMAC-2D in cases of a confined and relatively narrow river. In 2016, HEC-RAS 5.0 was officially released. With this version, it is possible to perform $1 \mathrm{D}-2 \mathrm{D}$ coupled computations.

Several studies have shown the applicability of 1D-2D flood modelling. Most software programs (e.g. Mike-11, HEC-RAS) that allow 1D-2D coupling are based on mass-conservation. The conservation of momentum is often neglected. Bladé et al. (2012) argue that neglecting the momentum in the coupling of a 1D profile and the 2D grid cells affects flow patterns in the floodplains in most cases. The more connected the river and the floodplains are, e.g. in case of overland flows, the more important momentum becomes since an increase in flow velocity results in an increase in momentum (Bladé et al. 2012). Conservation of momentum can only be neglected if the $1 \mathrm{D}$ profiles are coupled with $2 \mathrm{D}$ grid cells by a weir/embankment since the hypothesis of the Shallow Water equations are not fulfilled for this specific case (Bladé et al., 2012). With HECRAS, the weir-equation can be used to compute the flow over the embankment using the results of the 1D and 2D solution algorithms on a time step by time step basis. This allows for direct feedback at 
each time step between the 1D profiles and 2D grid ${ }_{465}$ 415 cells (Brunner, 2014). Neglecting conservation of momentum is justified for this modelling purpose since the $1 \mathrm{D}$ profiles are coupled with the $2 \mathrm{D}$ grid cells by an embankment. Hence, the 1D-2D coupling can be treated as a weir-type connection.

\subsubsection{Differences between the high-fidelity and lower-fidelity model}

A 1D-2D coupled model requires the same in- 475 put data as a fully $2 \mathrm{D}$ model. Therefore, we use the same input data of the high-fidelity model to set up the 1D-2D coupled model. The Digital Elevation model (DEM) of the $2 \mathrm{D}$ model is used to establish the 1D profiles and 2D grid cells of the 1D-2D coupled model. Also, the boundary conditions consisting of measured discharges and water levels, as well as the land use classification for both models are identical. Therefore, we can conclude that the differences in the representations of the input parameters of the high-fidelity and the lowerfidelity model are solely caused by the level of detail of the two models itself and the different settings of D-Flow FM and HEC-RAS. These differences are explained in more detail below and are summarized in Table 1

Firstly, the 2D Shallow Water equations of the high-fidelity model are simplified to the Diffusive Wave equations. The Diffusive Wave equations are applicable if flow separation and turbulence eddies can be neglected. This is the case if the inertial terms are much smaller than the gravity, friction and pressure terms. Test runs showed that neglecting the inertial terms of the momentum equations did not result in a change in model results. On the other hand, the use of the Diffusive Wave equations resulted in a significant reduction of the computational time. Therefore, the Diffusive Wave equations are used to compute the flow characteristics at each 1D profile and 2D grid cell. The applicability of the Diffusive Wave equations for flood modelling purposes has also been shown by e.g. Moya Quiroga ${ }^{50}$ et al. (2016), Moussa and Bocquillon (2009) and Leandro et al. (2014).

Secondly, the computational time step of the lower-fidelity model is increased compared to the fully $2 \mathrm{D}$ model to speed-up computational time. In 510 a $2 \mathrm{D}$ model, the river is usually the time step limiting factor since the depths and velocities in the main channel are larger than in the embanked areas (Bladé et al., 2012) (see equation 1). The high- fidelity model had an average time step of 3.9 seconds, based on the maximum Courant number. A fixed time step of five minutes can be used for the lower-fidelity model. This time step is based on a convergence argument: reducing the time step further did not result in a reasonable improvement of the model accuracy.

The land use classification of the high-fidelity model is used as input for the lower-fidelity model. D-Flow FM allows multiple roughness definitions to be implemented in a single model. However, HECRAS only allows a Manning's roughness coefficient for the various land use classes. Therefore, the roughness classes as used in the high-fidelity model were transformed towards Manning's roughness values based on Table 5-6: "Values of the roughness coefficient $n$ " of Chow (1959).

We recall that it is necessary to calibrate the summer bed roughness of the high-fidelity model, since each 2D grid has its own numerical friction. On the other hand, it is decided to not calibrate the lower-fidelity model. As a result, the summer bed roughness can be included in the sensitivity analysis as a random parameter. This is justified since no inundations along the Lower Rhine occurred during the 1926 flood event. Therefore, correct prediction of the water levels becomes irrelevant. The lower-fidelity model is set up to accurately predict maximum discharges at Lobith during flood events instead. During the simulation, the entire discharge wave flows in downstream direction independent of simulated water levels, since inundations are not possible to occur. Consequently, it is expected that simulated maximum discharges of the uncalibrated surrogate model are close to those predicted by the calibrated high-fidelity model. However, validation is recommended to study whether the lower-fidelity model is capable of simulating the system behaviour sufficiently.

\subsubsection{Validation lower-fidelity model}

Razavi et al. (2012b) argue that, even though the lower-fidelity model may be based on the same input parameters as the high-fidelity model, the response pattern can differ somewhat. This was also shown by Thokala and Martins (2007). They neglected the fluid viscosity in the Navier-Stokes equations to set up a lower-fidelity model. This resulted in less accurate results compared to the high-fidelity model. The discrepancies between the 
Table 1: Overview of the differences between the high and lower-fidelity model

\begin{tabular}{|l|l|l|}
\hline & High-fidelity model & Lower-fidelity model \\
\hline Software & D-Flow FM & HEC-RAS \\
\hline Dimension & Fully 2D & $\begin{array}{l}\text { 1D cross sections in summer bed and winter bed, } \\
\text { 2D in the embanked areas }\end{array}$ \\
\hline Nature & Shallow Water equations & Diffusive Wave equations \\
\hline Time step & $\begin{array}{l}\text { Variable time step based on } \\
\text { maximum Courant number }\end{array}$ & Fixed time step \\
\hline Roughness & Different roughness definitions & Manning's roughness coefficient \\
\hline Calibration & Calibrated summer bed roughness & Uncalibrated \\
\hline
\end{tabular}

515 response patterns of the lower-fidelity and highfidelity models mostly influence the local and global minimum and maximum of the system (Razavi et al., 2012b). Since this study tries to predict max- 555 imum discharges during a historic flood event, it is of high importance that the global maximum of the system is correctly modelled by the lower-fidelity model. If this is not the case, the discrepancies between the lower-fidelity and high-fidelity model 560 can be addressed with a correction function (Razavi et al., 2012b). These kind of functions correct the response of the lower-fidelity model and align it with the response pattern of the high-fidelity model. It is thus of high importance to validate the lower- 565 fidelity model to study whether a correction funcion is required to tune the model results.

If the response pattern of the lower-fidelity model is close to that of the high-fidelity model, the lower-fidelity model can be treated as the highfidelity representation of the underlying system. 570 Consequently, the lower-fidelity model can replace the sophisticated 2D model (Razavi et al. 2012b). The sensitivity analysis can then be safely performed with the lower-fidelity model since the input parameters of the lower-fidelity model are based on 575 the input parameters of the high-fidelity model.

\subsection{The 1926 casus}

The 1926 flood event of the Rhine river is used to examine the methodology of developing a lowerfidelity model for historic flood reconstruction. The study area stretches from the areas downstream of Andernach in Germany to the three Rhine river branches in the Netherlands (Fig. 5). In this pa- 585 per, the German part of the river is referred to as the Lower Rhine. The river enters the Netherlands at Lobith, where it bifurcates into the Waal river and Pannerdensch Canal. Subsequently, the Pannerdensch Canal bifurcates into the Nederrijn and IJssel rivers. Only the summer bed, its floodplains and two embanked areas that are connected by an inlet (Ooijpolder and Rijnstrangen area, (Fig. 5p) are captured in the model domain. The term inlet is used for a dike section with a relatively low crest level. Due to this low crest level, a part of the discharge wave will enter the lower-lying area behind the inlet as soon as a certain water level is exceeded. As a result, the maximum discharge further downstream decreases. The dikes represent the boundaries of the model domain and are assumed not to overflow.

\subsubsection{Geographical situation}

To reconstruct a historical geometry, the changes in the river system between the current geometry and the historical period of interest must be defined. An existing data set representing the 1995 geometry is made available by the Dutch Ministry of Infrastructure and Water Management. This data set is used as starting point and is adapted such that it represents the historical geometry. The following measures were taken to create the 1926 situation (Fig. 5):

- Increase summer bed level due to erosion. Measurements of the summer bed levels were available for the entire model domain. The changes in summer bed level between the 1995 measurements and the oldest measurements available at each location were used to estimate the 1926 summer bed level by linear extrapolation.

- Decrease winter bed level due to sedimentation. No measured sedimentation rates along the study area were available. Therefore, the following sedimentation rates 


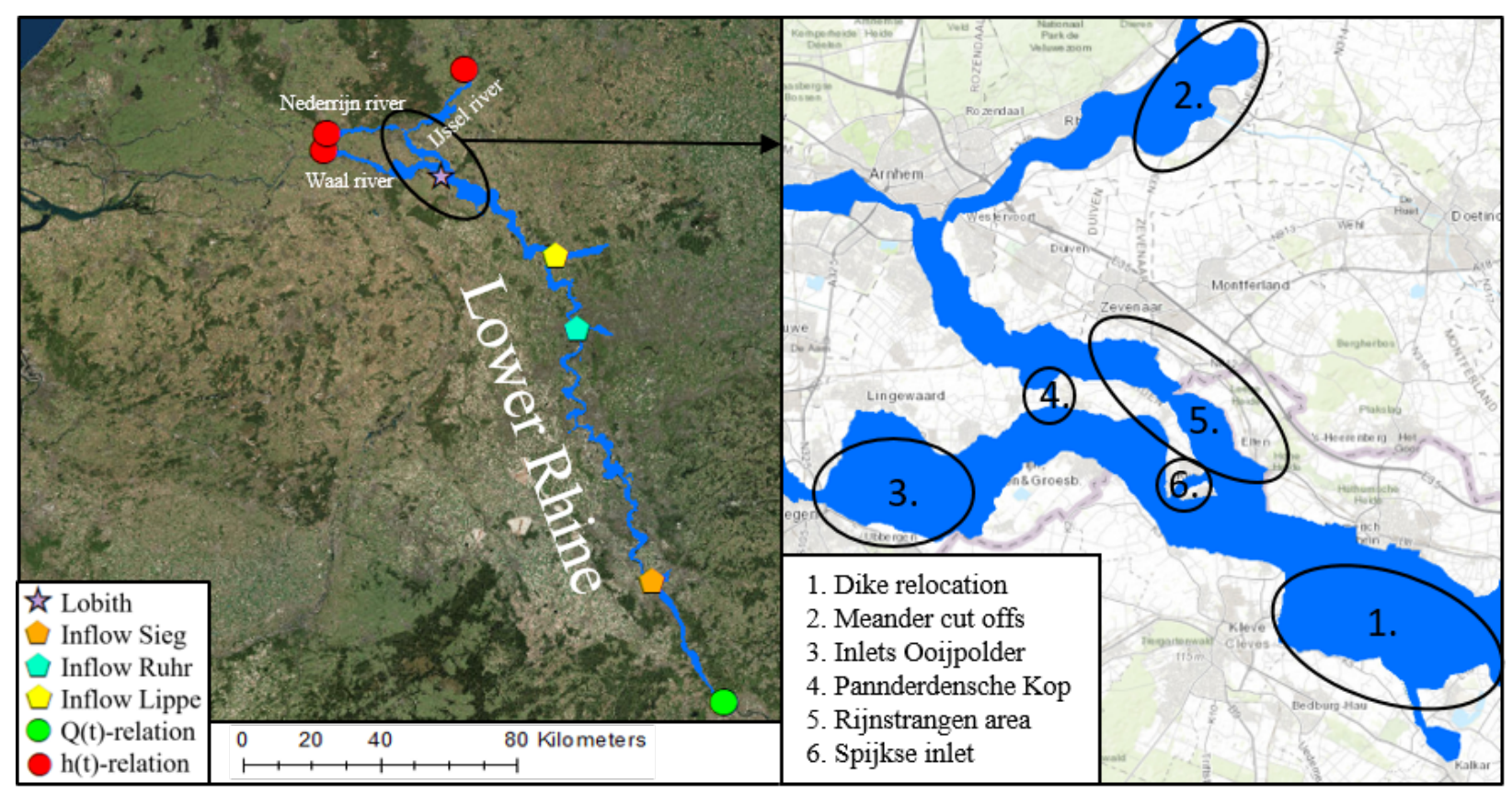

Figure 5: Boundaries of the study area and location of inflow (left figure) and location of artificial measures taken to change the 1995 geometry into the 1926 situation (right figure)

were used to predict the 1926 winter bed level: ${ }_{615}$ $1 \mathrm{~mm} /$ year along the IJssel river, Pannerdensch Canal and Lower Rhine, $3 \mathrm{~mm} /$ year along the Waal river and $0.5 \mathrm{~mm} /$ year along the Nederrijn river (Silva et al., 2001). A linear decrease of the sedimentation rate in channel cross direction was assumed. As a re- 620 sult, the sedimentation near the summer bed equals the predicted sedimentation rates according to Silva et al. (2001). The sedimentation near the outside border of the floodplain equals zero.

- Dike relocation. On the left side of the Lower Rhine, close to the city of Emmerich, Germany, the floodplains of the river were much larger in 1926 than they are nowadays. The 1926 dike locations and hence the 1926 winter bed were based on old maps dating back to 1895 (Fig. 5. Dike relocation), provided by the German Deichverband Xanten-KleveDer Oberdeichinspektor Dusseldorf (1895).

The current summer dikes along the Pannerdensch Canal close to the Pannerdensche Kop were the 1926 winter dikes. Therefore, the present floodplains were not part of the 1926 river system. The area outside the 1995 summer dikes were removed from the geometry (Fig. 5. Pannerdensche Kop).

- Restoration of inlets. In 1926, two retention areas were possible to inundate at high discharge stages as a result of inlets. The Spijke inlet caused inundation of the Rijnstrangen area when the water level exceeded $15 \mathrm{~m}+\mathrm{NAP}$, equal to the crest level of the inlet (Fig. 5, Rijnstrangen area).

In the Ooijpolder, three inlets were active. The total length of the inlets was $150 \mathrm{~m}$. The Ooijpolder started to inundate at a water level of $12.5 \mathrm{~m}+\mathrm{NAP}$, equalling the height of the three inlets. The location of the inlets was based on historical 1926 maps (Fig. 5, Ooijpolder).

- Restoration of meander cut offs. In 1955 and 1969 two meanders near Doesburg and Rheden were cut off (Fig. 5. Meander cut offs). Due to these meander cut offs the total length of the IJssel river decreased with almost nine kilometres. The location of the meander bends are based on historical 1926 maps. 


\subsubsection{Boundary conditions}

The 1926 flood event is simulated for a period of approximately three weeks, starting on the $22^{\text {nd }}$ of December 1925 till the $8^{\text {th }}$ of January 1926. From the $26^{\text {th }}$ of December onwards, the weather conditions changed drastically. High rainfall intensities ${ }^{695}$ occurred in almost the entire catchment area of the Rhine river (Dutch Ministry of Infrastructure and the Environment, 1926). This resulted in a rapid rise of the discharge wave, starting on the $27^{\text {th }}$ of December.

Fig. 6 shows the discharge wave at Andernach, representing the upstream boundary condition (Data source: German Federal Waterways and Shipping Administration (WSV), communicated by German Federal Institute of Hydrology (BfG)). The downstream boundary conditions consist of $\mathrm{h}(\mathrm{t})$-relations based on daily measured water levels 705 available at http://waterinfo.rws.nl and provided by the Dutch Ministry of Infrastructure and Wa-

${ }_{660}$ ter Management. Three streams enter the Lower Rhine, namely the Lippe, Ruhr and Sieg rivers. These streams were included in the model domain 710 by source points (discharge inflow, Fig. 5 and Fig. 6). The presented boundary conditions and source 665 points are used in both the high-fidelity as well as the lower-fidelity model to set up the models.

\section{Methodology of Sensitivity Analysis}

In this study uncertainty and sensitivity analyses are performed. An uncertainty analysis is executed to compute the maximum discharge at Lobith 720 with its standard deviation as a result of the uncertain input parameters. Next, a sensitivity analysis is performed to study which parameter mostly influence the uncertainty of the model output. The main objective of the sensitivity analysis is the so 725 called factor prioritization. With this prioritization, it becomes clear on which parameter to focus during historical geometry reconstruction for flood modelling purposes in order to reduce the potential uncertainty in the model output.

During the analyses, we only focus on the parameters that influence the maximum discharge at Lobith. A test run was performed in which all roughness parameters along the Dutch river branches were increased with $20 \%$. In this run, the 735 roughness values are close to the upper bound of the truncated normal distributions. The run showed that the increase in roughness resulted in only a minor decrease of the maximum discharge at Lobith of approximately $0.2 \%$, from 12,402 to $12,373 \mathrm{~m}^{3} / \mathrm{s}$. This minor decrease suggests that the Dutch river branches are sufficiently downstream such that the effects of different summer bed roughness on the maximum discharge are negligible. Therefore, the study only focuses on the uncertainties of the input parameters in the most upstream part of the model domain: the city of Andernach until the location where the Rhine river bifurcates into the Waal river and Pannderdench Canal. The Dutch Rhine river branches are seen as fixed boundary conditions of the model since they do not influence model response. Therefore, they can be excluded from the global sensitivity analysis.

\subsection{Input parameters}

The lower-fidelity model is used to establish the uncertainty and sensitivity of the 1926 discharge at Lobith. Only the input parameters that are based on an estimation, i.e. those that are uncertain, are included in the analysis. In addition, parameters that require the development of a new surrogate model when changed (e.g. a planometric change) are excluded from the analysis for pragmatic reasons. The following parameters are considered during the sensitivity analysis: (1) roughness paramethe bed levels of the summer bed and winter bed. In general, two kinds of uncertainties exist. The first uncertainty is as a result of the randomness of variations in nature (inherent uncertainty). The second uncertainty is caused by limited knowledge (epistemic uncertainty) (Warmink et al., 2013). The uncertainty of the different roughness classes is mainly caused by inherent uncertainty since it depends amongst others on the season (e.g. grass grows faster during summer periods resulting in a larger roughness) as well as on maintenance (e.g. the frequency of mowing grass fields). The uncertainty of the summer bed and winter bed levels are caused by epistemic uncertainty. No measured 1926 bed levels 730 extrapolation techniques and estimated sedimentation rates.

For all roughness parameters, we link the value with the largest probability of occurrence as well as its minimum and maximum bounds to the tables of Chow (1959). Truncated normal distributions are used in this study since a normal distribution better fits the data if some information about the input parameters is available (tails of the distribution 

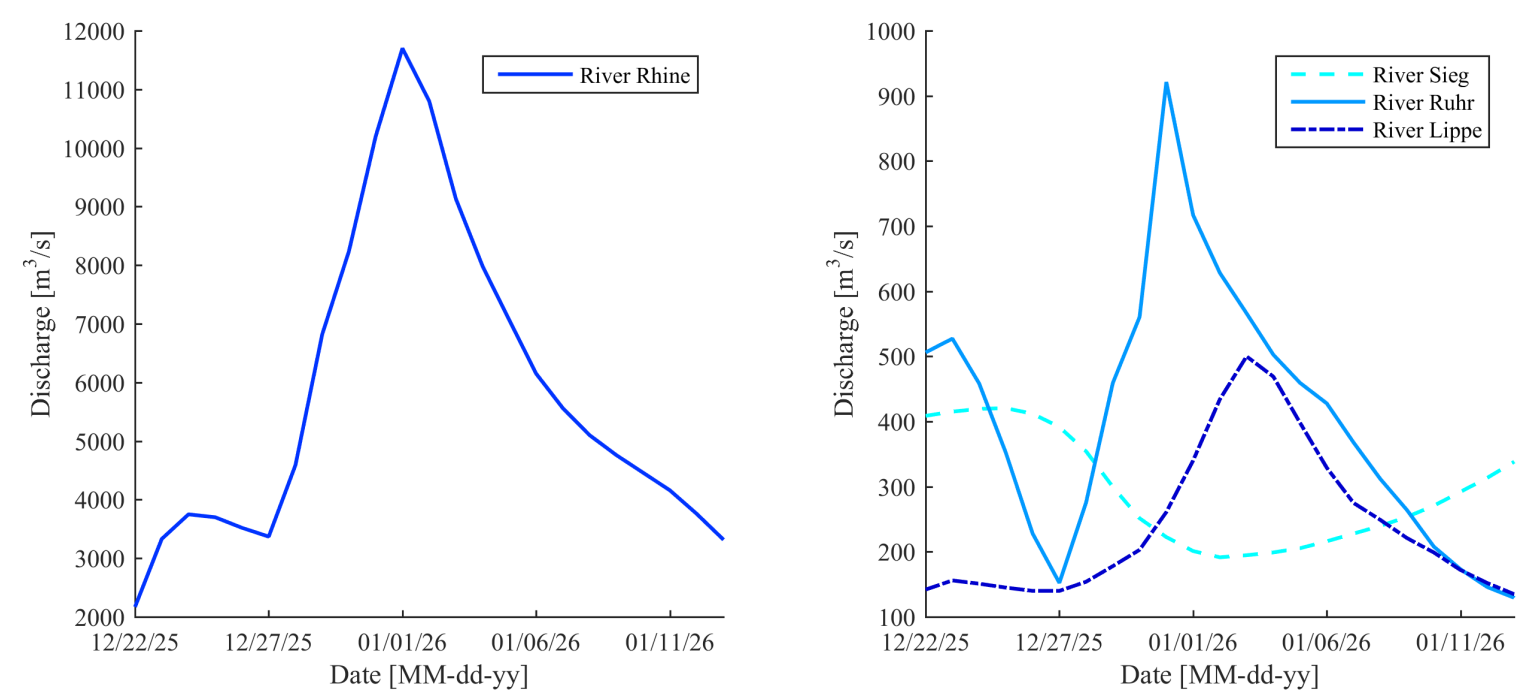

Figure 6: Discharge waves of the Rhine river at Andernach (left figure) and the three tributaries Sieg, Ruhr and Lippe (right figure). Note: only daily discharge measurements are available resulting in the sharp peaks of the different discharge waves

and the expected value). Contrarily, a uniform distribution assumes that there is no knowledge about 770 the value with the largest probability of occurrence. Only a range of input values is known. Therefore, we can conclude that for older historic events, the distributions of the uncertain input parameters will shift towards uniform distributions since less and less information is available.

The roughness parameters are divided into five land use classes: summer bed, lakes, grasslands, forest and urban areas. A smooth channel with no vegetation is assumed for the entire summer bed, 780 having a minimum Mannings roughness of 0.025 , a normal value of 0.028 which is used as the expected value, and a maximum value of 0.033 (Chow, 1959). These numbers are used to set up the truncated normal distribution. The same method was used 785 to define the truncated normal distributions of the other roughness classes (Table 2).

A comparable method is used to set up the truncated normal distributions of the summer bed levels and winter bed levels. The 1926 summer bed levels were computed based on extrapolation of measured bed level changes (see Section 2.3). The uncertainty ranges of the summer bed levels were based on these extrapolation values. The minimum change in bed level corresponds to no change compared to the old- 795 est measured bed value. Consequently, the 1926 bed level equals the oldest measured bed level. The maximum change in bed level equals the extrapolation of the trend between 1995 and the latest measured bed level multiplied with a factor two. A factor of two is chosen to include a large uncertainty range. The summer bed is divided into three classes:

1. From the most upstream location Andernach (river km 614) until Walsum (river km 789). Here, almost no erosion has occurred between 1995 and 1926. Additionally, the bed level has been compensated for bed level decrease due to mining activities at several locations.

2. From Walsum until the German-Dutch border (river $\mathrm{km} \mathrm{857).} \mathrm{Here,} \mathrm{there} \mathrm{is} \mathrm{relatively}$ much uncertainty in the amount of erosion since the oldest measured bed level dates back to only 1960.

3. From the German-Dutch border till the first bifurcation point of the Rhine river (river $\mathrm{km}$ 867). Here, there is little uncertainty in the 1926 bed level since the oldest measurements date back to 1934 .

The winter bed level consists of just one class since no deviations in uncertainty along the Lower Rhine exist. The estimated sedimentation rate of 1 $\mathrm{mm} /$ year is used to define the ranges of the winter bed level in the Lower Rhine (Silva et al., 2001). The minimum value equals no change in bed level compared to the 1995 situation. The maximum 
Table 2: Minimum, Maximum and Standard deviation of the different input parameters

\begin{tabular}{|l|c|c|c|}
\hline Input parameter & Minimum value & Maximum value & Standard deviation \\
\hline Summer bed & 0.025 & 0.033 & 0.002 \\
Lakes & 0.024 & 0.034 & 0.003 \\
Graslands & 0.037 & 0.075 & 0.009 \\
Forest & 0.098 & 0.178 & 0.020 \\
Urban areas & 0.029 & 0.039 & 0.003 \\
St. Winter bed level & $-0.070 \mathrm{~m}$ & $0.070 \mathrm{~m}$ & $0.035 \mathrm{~m}$ \\
St. Summer bed level (1) & $-0.150 \mathrm{~m}$ & $0.150 \mathrm{~m}$ & $0.075 \mathrm{~m}$ \\
St. Summer bed level (2) & $-0.520 \mathrm{~m}$ & $0.520 \mathrm{~m}$ & $0.260 \mathrm{~m}$ \\
St. Summer bed level (3) & $-0.090 \mathrm{~m}$ & $0.090 \mathrm{~m}$ & $0.045 \mathrm{~m}$ \\
\hline
\end{tabular}

range equals the sedimentation rate of $1 \mathrm{~mm} /$ year 835 multiplied with a factor of two. Again a factor of wo is chosen to include a large uncertainty range since the $1 \mathrm{~mm} /$ year sedimentation rate is relatively speculative. Since the summer bed and winter bed levels vary along the study area, their truncated normal distributions and corresponding minimum and maximum values are given as change from its 1926 reference value (Table 2). These values will be referred to as Standardized (St.) bed levels from now on. A value equal to zero correspond with the reconstructed 1926 geometry.

\subsection{Design of Experiment}

Before a sensitivity analysis can be performed, a Design of Experiment (DoE) has to be defined. DoEs employ different space filling strategies to capture the behaviour of the underlying system over limited ranges of the input parameters (Razavi et al., 2012b). A DoE results in a sample in which the boundary values of the input parameters are based on physical conditions. This sample can be used in a Monte Carlo analysis. Most commonly used DoE methods in literature appear to be full factorial design, fractional factorial design, central composite design and latin hypercube sampling (LHS) (Razavi et al., 2012b). In general, a full factorial design, a fractional factorial design and a central composite design require a relatively large number of simulations to generate all combinations to represent the corners of the input space (Razavi 865 et al., 2012b; Saltelli et al., 2008). Contrarily, LHS can easily scale to different numbers of input parameters without the need for extra simulation runs (Razavi et al. 2012b). Thus, a stratified LHS sample has as advantage that less model runs are re- 870 quried since a stratified sample achieves a better coverage of the sample space of the input parame- ters (Saltelli et al., 2000). For this reason, a LHS design is used in this study.

The nine input parameters are divided into eight levels. Each level has an equal probability of occurrence of $12.5 \%$, based on the determined truncated normal distributions in Section 3.1. For each run, each level is randomly selected, constraining that if a level is already selected it cannot be selected again. This results in a set of eight simulations in which all eight levels of the nine input parameters are present.

No clear guidelines exist concerning the minimal number of runs required in a Monte Carlo analysis. This number depends on the number and range of the input parameters and on the shape of the response surface. Theses features are largely unknown in advance (Pappenberger et al., 2005). In this study convergence of the uncertainty of the discharge at Lobith, expressed as standard deviation, is used as stopping-criteria, following the method of Pappenberger et al. (2005). If an additional run results in a change of the standard deviation smaller than $0.05 \mathrm{~m}^{3} / \mathrm{s}$, it is assumed that the sample sufficiently represents the input space of the different input parameters. This criteria resulted in 120 model runs, corresponding with 15 latin hypercube sets.

To check whether the input space is sufficiently captured by the sample, two additional model runs were performed with the most extreme situations. These scenarios represent the limits of the probability distribution functions of the input parameters. Table 3 and Fig. 7 show the range of maximum discharges at Lobith modelled in the 120 Monte Carlo runs and the range found with the two most extreme cases. Note that all runs are performed with the lower-fidelity surrogate model. The minimum and maximum values of the sample are close to the predicted values of the two most extreme 
Table 3: Minimum and Maximum discharge at Lobith $\left(\mathrm{Q}_{\min , \text { Lobith }} / \mathrm{Q}_{\mathrm{max}, \text { Lobith }}\right)$ as a result of the two most extreme model runs and the 120 runs within the Monte Carlo (MC) analysis

\begin{tabular}{|l|c|c|c|}
\hline & Extreme case & MC runs & Difference \\
\hline $\mathrm{Q}_{\min , \text { Lobith }}\left[\mathrm{m}^{3} / \mathrm{s}\right]$ & 12,285 & 12,293 & 17 \\
$\mathrm{Q}_{\max , \text { Lobith }}\left[\mathrm{m}^{3} / \mathrm{s}\right]$ & 12,548 & 12,531 & 8 \\
\hline
\end{tabular}

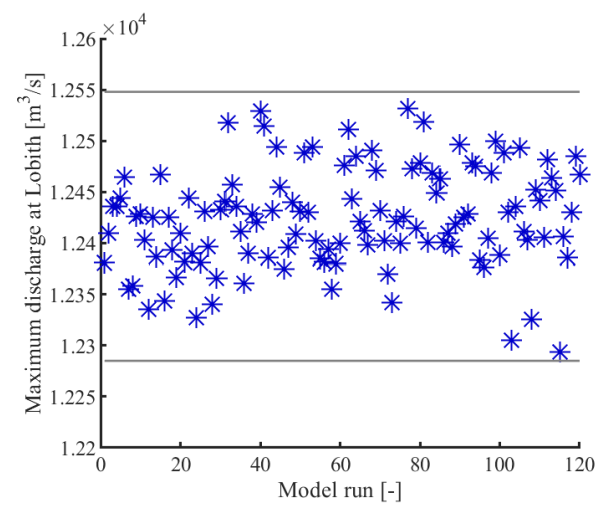

Figure 7: Input space of the LHS representing the maximum discharges at Lobith modelled during each model run. The grey lines indicate the results of the two most extreme model runs

runs. Therefore, we can conclude that the input space is sufficiently captured by the sampling data 895

\subsection{Stratified Monte Carlo analysis}

The results of the Monte Carlo analysis are used ${ }_{900}$ to determine the uncertainty in model predictions. Additionally, the results are used to apportion this uncertainty to the contribution of the individual input parameters. Two sensitivity analysis methods are used, namely Multiple Linear Regression analysis and Sobol' indices explained in Sections 3.3.1 and 3.3 .2 respectively.

\subsubsection{Multiple Linear Regression Analysis}

If the number of simulations is much larger than the number of input parameters, a LHS can be very effective in revealing the influence of each parameter using a regression analysis (Saltelli et al., 2008). If the model does not contain any interactions between the input parameters (i.e. the model is additive), the linear regression function can be given as 910 (Scheidt et al. 2018):

$$
y=\beta_{0}+\sum_{i=1}^{N} \beta_{\mathrm{i}} x_{\mathrm{i}}
$$

where $y$ represents the model output (in this study the maximum discharge at Lobith) and $x_{i}$ the different input parameters. The coefficients $\beta_{0}$ and $\beta_{\mathrm{i}}$ are determined by the least-square computation, based on the squared differences between the model output produced by the regression model and the actual model output produced by the surrogate model (Saltelli et al. 2008).

The coefficient $\beta_{\mathrm{i}}$ is used to determine the importance of each parameter $x_{i}$ with respect to the model output. If the input parameters are independent, the absolute standardized regression coefficient $\hat{\beta}_{\text {i }}$ can be used as a measure of sensitivity (Scheidt et al. 2018):

$$
\hat{\beta}_{\mathrm{i}}=\left|\beta_{\mathrm{i}} \frac{\sigma_{\mathrm{i}}}{\sigma_{\mathrm{y}}}\right|
$$

where $\hat{\beta}_{\text {i }}$ represents the standardized regression coefficient, and $\sigma_{\mathrm{i}}$ and $\sigma_{\mathrm{y}}$ represent the standard deviations for the input parameter $x_{i}$ and the model output respectively.

However, the applicability of a linear regression analysis depends on the degree of linearity of the model (Saltelli et al., 2008). A measure for linear- 


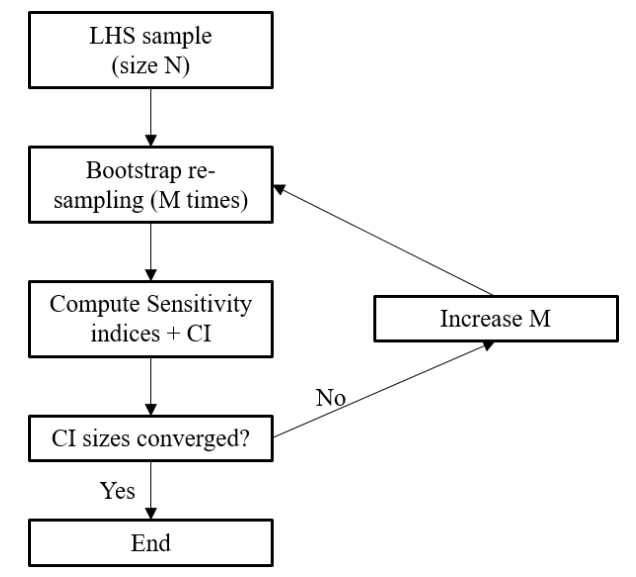

Figure 8: Bootstrap method for resampling in which CI stands for confidence intervals

ity is expressed by (Saltelli et al., 2008):

$$
R^{2}=\sum_{i=1}^{N}\left(\hat{\beta}_{\mathrm{i}}\right)^{2}
$$

where $R^{2}$ represents the model coefficient of deter- ${ }^{945}$ mination. This value is equal to the fraction of the variance of the original data that is explained by the regression model. A value of $R^{2}$ equal to one indicates that the model is linear (Saltelli et al. 2008) and that the multiple linear regression model 950 is capable of expressing all variance of the original data.

\subsubsection{Sobol' indices}

If the model is not linear, Sobol' indices can be used to determine the sensitivity of the input parameters. Sobol' indices are widely used as global sensitivity analysis method in literature. We are 960 specifically interested in the first-order indices, i.e. the effect without interactions of input parameters, since the sensitivity analysis is used for factor prioritization purposes (Saltelli et al., 2008). Li and Mahadevan (2016) present an effective method to 965 estimate the first-order Sobol' indices analytically. This method can be applied to any kind of data set and is not restricted to a specific sampling strategy. Furthermore, the method can be applied to models with correlated input parameters. Li and Mahade- 970 $\operatorname{van}(2016)$ found that the method is highly efficient and that it is especially useful in ranking and identifying important parameters. The formula used is as follow (Li and Mahadevan, 2016):

$$
S_{\mathrm{i}}=1-\frac{E_{\mathrm{xi}}\left(V_{\mathrm{x}-\mathrm{i}}\left(y \mid x_{\mathrm{i}}\right)\right)}{V_{\mathrm{y}}}
$$

where $S_{\mathrm{i}}$ represents the Sobol' first-order index, $V_{\mathrm{x}-\mathrm{i}}\left(y \mid x_{\mathrm{xi}}\right)$ indicates the conditional variance of $\mathrm{y}$ caused by all input parameters other than $x_{\mathrm{i}}, E_{\mathrm{xi}}$ represents the expected value as a result of fixing input parameter $x_{\mathrm{i}}$, and $V_{\mathrm{y}}$ represents the variance of $\mathrm{y}$.

The Monte Carlo sample has a relatively small size. Therefore, the $95 \%$ confidence intervals of the Sobol' indices are computed based on a resampling strategy. The MATLAB Statistics Toolbox is used to perform the computation. The method to compute the $95 \%$ confidence intervals is based on the 5 work of Dubreuil et al. (2014) in which a bootstrap resampling strategy is used. Computation of confidence intervals by bootstrap resampling is widely used in global sensitivity analysis and has been used in combination with surrogate models by Gayton et al. (2003) and Janon et al. (2011). Bootstrap resampling aims at determining confidence intervals of a parameter of interest using only one design of experiment (Efron and Tibshirani, 1993). The method consists of the creation of new designs of experiment by drawing with replacement in the original design.

The method used is presented in Fig. 8. The LHS sample consisting of 120 model runs is resampled, after which the confidence intervals of the first-order Sobol' indices are computed. If these confidence intervals have not reached a specific convergence criterion yet, more bootstrap resamples are drawn. The computation is repeated until the 
convergence criterion is met. The criterion as suggested to stop the procedure at the iteration for 1025 which all confidence interval sizes have reached a range which is less than $\mathrm{x}$ percent of the maximum bootstrap mean of the sensitivity indices. The choice of parameter $\mathrm{x}$ depends on the goal of the sensitivity analysis. If the goal is only determining 1030 the most dominant input parameter, a relatively large value of $\mathrm{x}$ in the order of $30 \%$ can be used. However, if the model has many variables of equal sensitivity indices, it is better to look at the convergence graph at each bootstrap iteration and decide manually when to stop the procedure (Dubreuil et al. 2014). The first convergence criteria (30\%) is used which will be evaluated by checking the convergence graphs of the Sobol' indices as suggested by Dubreuil et al. (2014).

\section{Results}

\subsection{Calibration high-fidelity model}

The river branches Lower Rhine, Waal river and

Pannerdensch Canal were calibrated with the use of ${ }_{104}$ measured water levels. The discharge partitioning along the Dutch river branches was based on the report of the Dutch Ministry of Infrastructure and the Environment (1952). During the calibration proedure, this discharge partitioning had to be met. 1050 The IJssel and Nederrijn rivers were excluded from the calibration procedure since many inundations along the IJssel river have occurred during the 1926 flood event. These inundations influence the water levels at both river branches. Even a very low sum- 1055 mer bed roughness near the locations of the inundations did not result in the correct water levels. For this study purpose, it is accepted that the water levels along the IJssel and Nederrijn rivers were not calibrated correctly. These branches are located 1060 more than $15 \mathrm{~km}$ downstream of Lobith such that backwater effects has vanished at Lobith. The IJssel and Nederrijn rivers have thus no effect on the maximum discharge at this location.

In the data set, only daily measured water levels 1065 are available. Hence, the maximum measured water level may be lower than the occurred maximum water level. Therefore, we calibrated on the three days with the highest water levels for each measurement station present along the river branches. If the 1070 model is capable of predicting the correct shape and correct water levels at three moments in time near the peak discharge, it is likely that also the correct maximum water level is predicted by the model.

The 1926 discharge wave was simulated. Maximum water levels at 10 measurement stations were validated after model calibration. It was found that simulated maximum water levels only deviated $2 \mathrm{~cm}$ on average compared to the measurements. Therefore, it can be concluded that the high-fidelity model is capable of simulating maximum water levels with high accuracy after calibration of the summer bed roughness.

\subsection{Validation and uncertainty of the lower-fidelity model}

The model output was compared with the model output of the high-fidelity model to study whether it is justified to use the lower-fidelity model to perform the sensitivity analysis. We found that 1040 charge at Lobith of $12,282 \mathrm{~m}^{3} / \mathrm{s}$ with the 1926 measured discharge wave at Andernach as upstream boundary condition. The lower-fidelity model, with all random input parameters set to their expected value, predicts a maximum discharge of 12,402 $\mathrm{m}^{3} / \mathrm{s}$. This deviates less than $1.0 \%$ compared to the high-fidelity model. Although, correct prediction of the maximum discharge at Lobith has the focus in this study, it is also desirable that the lower-fidelity predicts correct discharge stages at other locations. Table 4 shows that the lower-fidelity model predicts maximum discharges along the Lower Rhine with high accuracy, having a maximum deviation of $2.1 \%$ compared to the high-fidelity model. In addition, the lower-fidelity model is capable of accurately predicting the discharge partitioning along the Dutch Rhine river branches (Table 4). These values indicate that the surrogate model is capable of representing the system behaviour of the highfidelity model. Therefore, no correction-function is needed to tune the model results of the lowerfidelity model. We can thus conclude that the lower-fidelity model can be treated as a high-fidelity model from now on. Hence, the sensitivity analysis can be performed with the 1D-2D coupled model.

The results of the uncertainty analysis show that the average maximum discharge at Lobith as a result of the Monte Carlo sample equals 12,424 $\mathrm{m}^{3} / \mathrm{s}$. This value has a standard deviation of 49 $\mathrm{m}^{3} / \mathrm{s}$ caused by the uncertainty in the input parameters. This relatively low standard deviation shows that uncertainties in the input parameters 
Table 4: Maximum discharges along the Lower Rhine and discharge partitioning along the Dutch Rhine river branches predicted by the high-fidelity and lower-fidelity model, where $\mathrm{Qmax}_{\max }$ represents the maximum discharge at the specific location

\begin{tabular}{|l|c|c|c|}
\hline & $\begin{array}{c}\text { High-fidelity } \\
\text { model }\end{array}$ & $\begin{array}{c}\text { Lower-fidelity } \\
\text { model }\end{array}$ & Difference [\%] \\
\hline $\mathrm{Q}_{\max }$ Bonn $\left[\mathrm{m}^{3} / \mathrm{s}\right]$ & 11,509 & 11,580 & 0.6 \\
$\mathrm{Q}_{\max }$ Cologne $\left[\mathrm{m}^{3} / \mathrm{s}\right]$ & 11,632 & 11,715 & 0.7 \\
$\mathrm{Q}_{\max }$ Dusseldorf $\left[\mathrm{m}^{3} / \mathrm{s}\right]$ & 11,365 & 11,598 & 2.1 \\
$\mathrm{Q}_{\max }$ Rees $\left[\mathrm{m}^{3} / \mathrm{s}\right]$ & 12,351 & 12,572 & 1.8 \\
$\mathrm{Q}_{\max }$ Emmerich $\left[\mathrm{m}^{3} / \mathrm{s}\right]$ & 12,297 & 12,453 & 1.3 \\
$\mathrm{Q}_{\max }$ Lobith $\left[\mathrm{m}^{3} / \mathrm{s}\right]$ & 12,282 & 12,402 & 1.0 \\
\hline Waal river $[\%]$ & 70.3 & 71.9 & 1.5 \\
Pannerdensch Canal $[\%]$ & 29.7 & 28.0 & 1.7 \\
Nederrijn river [\%] & 58.7 & 56.2 & 2.4 \\
IJssel river [\%] & 41.4 & 43.8 & 2.4 \\
\hline
\end{tabular}

Table 5: Results Multiple Linear Regression analysis in which the most influential parameter has a ranking equal to 1 and the most non-influential parameter a ranking equal to 9

\begin{tabular}{|l|l|c|c|c|c|c|}
\hline \multicolumn{2}{|c|}{ Input parameter } & $\beta_{\mathrm{i}}$ & $\sigma_{\mathrm{i}}\left[\mathrm{m}^{3} / \mathrm{s}\right]$ & $\hat{\beta}_{\mathrm{i}}$ & Ranking & $\begin{array}{c}\text { Surface } \\
\text { area [\%] }\end{array}$ \\
\hline Roughness class & Summer bed & $-3.65 \times 10^{3}$ & $1.97 \times 10^{-3}$ & 0.15 & 2 & 13.3 \\
& Lakes & $-1.81 \times 10^{3}$ & $2.68 \times 10^{-3}$ & 0.10 & 5 & 13.2 \\
& Grasslands & $-4.81 \times 10^{3}$ & $8.71 \times 10^{-3}$ & 0.86 & 1 & 55.6 \\
& Forest & $-2.83 \times 10^{2}$ & $1.95 \times 10^{-2}$ & 0.11 & 4 & 6.4 \\
& Urban areas & $-2.29 \times 10^{2}$ & $2.73 \times 10^{-3}$ & 0.01 & 7 & 11.4 \\
\hline Bed level & Winter bed & -70.3 & $3.18 \times 10^{-2}$ & 0.05 & 6 & \\
& Summer bed (1) & 1.2 & $7.00 \times 10^{-2}$ & 0.00 & 9 & \\
& Summer bed (2) & 27.5 & 0.25 & 0.13 & 3 & \\
& Summer bed (3) & 8.3 & 0.04 & 0.01 & 8 & \\
\hline
\end{tabular}

only have a limited effect on the maximum discharge at Lobith during the 1926 flood event.

\subsection{Sensitivity analysis}

\subsubsection{Multiple linear regression analysis}

A multiple linear regression analysis was per- 1095 formed in which it was assumed that the model response as a result of the varying input parameters was linear. This is not the case since the model coefficient of determination $R^{2}$ (equation 4 equals 0.81 . This value means that the regression model is capable of explaining $81 \%$ of the variance 1100 of the surrogate output. The remaining $19 \%$ is ignored by the regression model. However, Table 5 clearly shows that the roughness of grasslands highly influences the maximum discharge at Lobith because of its high sensitivity measure $\hat{\beta}_{\mathrm{i}}$ (equation 1105
3). The high standardized regression coefficient of the roughness of grasslands can be explained by the fact that grassland is the most dominant land cover in the model domain with a surface area of $55.6 \%$ (Table 5). In addition, the uncertainty within the class itself is relatively large (Table 2 since grasslands most often have a higher roughness during summer periods due to growing season compared to the winter periods. Only the roughness of forest has a larger uncertainty range. However, the surface area covered by forest is much less (6.4\%).

\subsubsection{Sobol' indices}

In the previous section it was shown that with the Multiple Linear Regression analysis only $81 \%$ of the variance of the surrogate model output could be explained. In order to check the results of the Multiple Linear Regression analysis, the Sobol' in- 


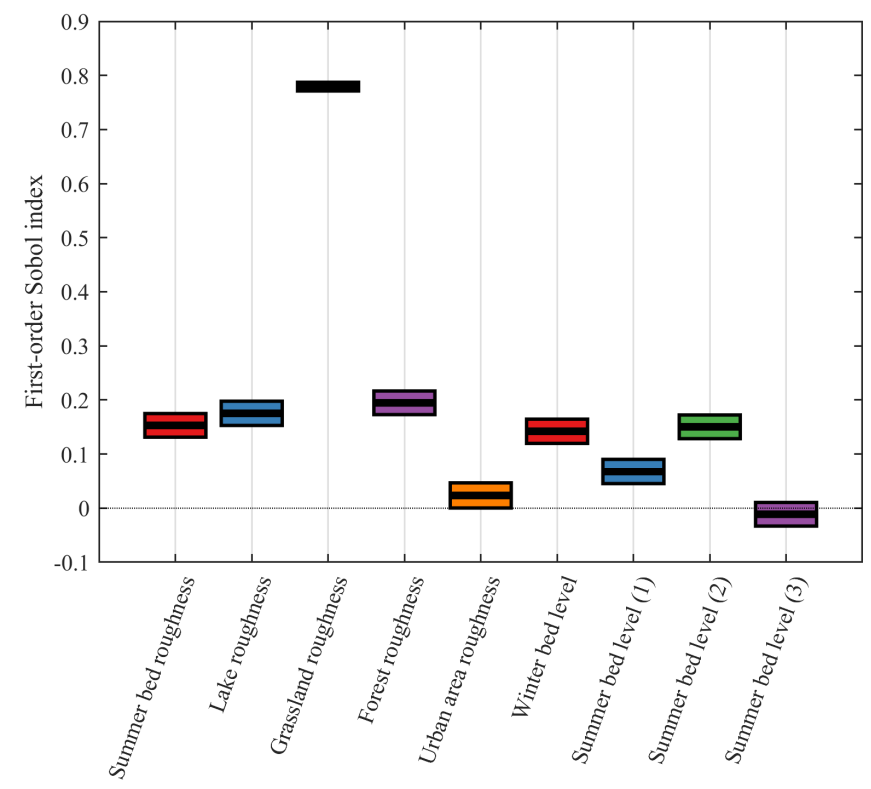

Figure 9: First-order Sobol' indices and its 95\% confidence intervals based on the bootstrap resamples

dices are computed. These indices are independent of model linearity. The results show that the roughness of grasslands is dominant with respect to influencing the uncertainty of the maximum discharge 1120 at Lobith (Table 6). This is in line with the results of the Multiple Linear Regression analysis.

If $\sum_{i=1}^{r} S_{\mathrm{i}}=1$, the variance of the model output is solely caused by the variance of the input parameters itself. In that case, there are no interactions between the different input parameters resulting in ${ }^{1125}$ an increase in the variance of the model output.
In other words, the model is additive. The results show that the first-order Sobol' indices are approximately 1 indicating that the model does not include any interactions of the input parameters.

In principle $\sum_{i=1}^{r} S_{\mathrm{i}}$ cannot be larger than 1 . In addition, the first-order Sobol' index computed for each uncertain input parameter cannot be lower than 0 (Saltelli et al. 2008). In this study, the computed $\sum_{i=1}^{r} S_{\mathrm{i}}$ is slightly larger than 1 and the Sobol' index for the roughness of urban areas is

Table 6: Computed Sobol' indices with the method of Li and Mahadevan $(2016)$ in which the most influential parameter has a ranking equal to 1 and the most non-influential parameter a ranking equal to 9

\begin{tabular}{|l|l|c|c|c|}
\hline \multicolumn{2}{|c|}{ Input parameter } & $\mathrm{S}_{\mathrm{i}}$ & Ranking & $\begin{array}{c}\text { Surface } \\
\text { area [\%] }\end{array}$ \\
\hline Roughness class & Summer bed & 0.10 & 2 & 13.3 \\
& Lakes & 0.01 & 7 & 13.2 \\
& Grasslands & 0.77 & 1 & 55.6 \\
& Forest & 0.05 & 5 & 6.4 \\
& Urban areas & -0.03 & 9 & 11.4 \\
\hline Bed level & Winter bed & 0.09 & 3 & \\
& Summer bed (1) & 0.01 & 8 & \\
& Summer bed (2) & 0.06 & 4 & \\
& Summer bed (3) & 0.03 & 6 & \\
\hline
\end{tabular}


smaller than 0 . This is caused by the relatively little sample size of only 120 runs. To overcome this problem, we resampled the 120 runs as explained 95\% confidence intervals of the first-order Sobol' in- 1180 dices are computed (Fig. 9). Fig. 10 shows that the first-order Sobol' indices have converged after approximately 700 bootstrap resamples. This reults in a data set of $700 \times 120$ model runs. The outcomes then show that the roughness of grass- 1185 lands remains the most dominant input parameter. The lower bound of its confidence interval is under any condition larger than the sensitivity index of the other input parameters. Therefore, we can conclude that for this specific case, most attention 1190 must be paid to the roughness class with the largest surface area and which has a relatively large uncertainty range. Correct prediction of this parameter will result in a significant reduction of the output variance. It must be noted that the uncertainty of ${ }_{1195}$ the model output was small in this study. In general, the output variance depends on the probability distribution functions of the uncertain input parameters. It can be expected that the output variance will increase for older historic events. Hence, a sig- 1200 nificant reduction in model output variance can be reached if the most influential input parameter is correctly predicted. This influential input parameter can be found by applying the method for factor prioritization as presented in this study.

\section{Discussion}

In this study, a methodology was developed to reconstruct historic flood events with the use of a ${ }^{1210}$ lower-fidelity model. The maximum discharge is predicted as well as its uncertainty as a result of the uncertain input parameter. General problems that arose were mostly related to the choice of the surrogate model type and the characteristics of the ${ }^{1215}$ ovent. Therefore, another historic event may ask for a different approach since the assumptions made for the 1926 event may not apply. To put things into perspective, an overview and discussion are presented of the problems that may arise during ${ }^{1220}$

1170 historic flood reconstruction and resulting sensitivity analysis.

1. To predict a historic discharge, an associated geometry should be reconstructed. The ge- 1225 ometry during the 1926 event was well known since maps of this time period are available.
However, for events further in the past the geometry might be more uncertain. These spatial uncertainties must be included in the analyses. A major drawback is that for each (uncertain) geometric situation a separate model must be set up. Consequently, for each model, the sensitivity analysis must be performed separately. This significantly increases the total number of simulations. Furthermore, for older events the uncertainties in the input parameters may become larger. Hence, the shape of their probability distributions may change. We assumed that the uncertain input parameters of the 1926 flood event could be described by truncated normal distributions. These distributions will shift towards uniform distributions for older events if less information is available.

2. A lower-fidelity based surrogate model was developed to reduce computational time. Many other methods exist to set up a surrogate model, each with their own benefits and drawbacks. A different study approach may lead to the need of another type of surrogate model. In general, a 1D-2D coupled model is capable of simulating any kind of flood event. The 1D profiles enable correct prediction of discharge stages below bankfull conditions (Horritt and Bates, 2002). These $1 \mathrm{D}$ profiles can be coupled by $2 \mathrm{D}$ grid cells to include the possibility of simulating overland flows if the discharge exceeds the bankfull discharge, referring to the situation in which the discharge is larger than the main channel and floodplain capacity. Therefore, this type of lower-fidelity model can be used to accurately simulate flood wave propagation for both discharges below as well as above bankfull conditions.

3. The 1D-2D coupled model was not calibrated on maximum water levels. The objective of the surrogate model was accurate prediction of maximum discharges at Lobith. However, calibration on maximum water levels is required if dike breaches and/or overtopping have evolved during the flood event. For such a case, correct prediction of maximum water levels becomes important since this value indicates whether overtopping occurs. This influences the maximum discharge further downstream. Therefore, it is recommended to use the summer bed roughness of 


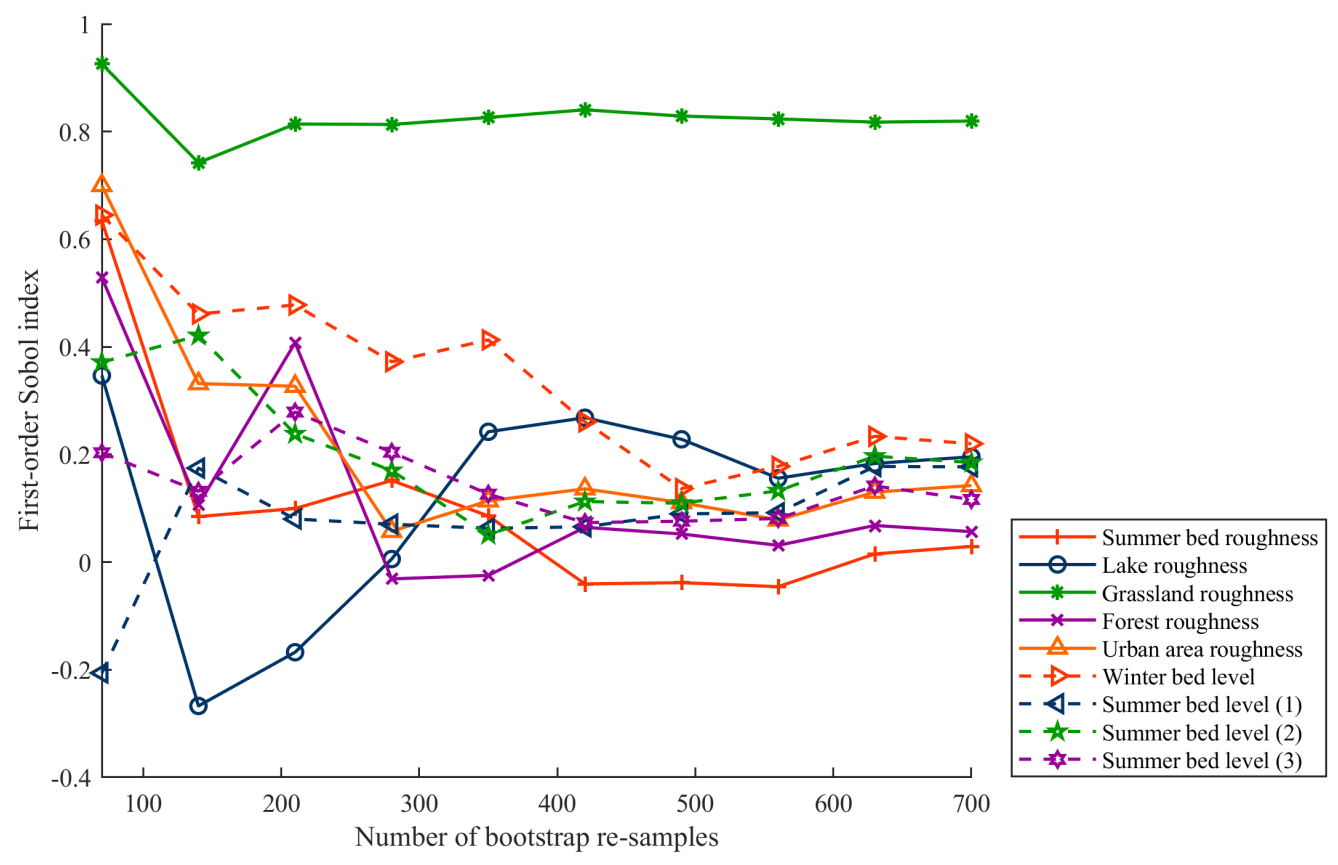

Figure 10: Convergence of the first-order Sobol' indices based on the bootstrap resamples

the lower-fidelity model as calibration parameter to correctly predict water levels in case 1255 of discharges exceeding bankfull conditions.

4. To perform the sensitivity analysis, a decision had to be made about the range of the truncated normal distributions of the input parameters. The ranges of the roughness pa- ${ }^{1260}$ rameters were based on the tables of Chow (1959). A smooth channel with no vegetation was assumed to determine the roughness of the summer bed. This results in a relatively low expected Mannings roughness ${ }^{1265}$ value of 0.028 , with a total range of between 0.023 to 0.033 . It is expected that the dimensions of sand dunes during flood events are highly uncertain. This uncertainty may influence summer bed roughness significantly. The ${ }^{1270}$ measured Mannings roughness of the summer bed during the 1998 event with a maximum discharge of $9,464 \mathrm{~m}^{3} / \mathrm{s}$ at Lobith ranges of between 0.030 to 0.035 (Julien et al., 2002). These values are higher than the values that ${ }^{1275}$ we used. Paarlberg et al. (2010) found a clear dependency between increase in the discharge and increase in the dune heights. However, it is still unclear to what extent dune heights increase during flood events. Some literature even suggest that the dunes are washed out under extreme conditions (e.g. Best (2005) and Naqshband et al. (2014)), resulting in much lower values of the roughness parameter. It is not the roughness value itself that influences the uncertainty of the maximum discharge, but rather the uncertainty range of the summer bed roughness. Therefore, the relatively broad roughness range for the summer bed used in this study is considered appropriate for the 1926 flood event. In this study, only geometrical uncertainties in the input parameters are included in the sensitivity analyses. These parameters are the bed levels of the summer bed and winter bed and the roughness of the various land use classes. However, much more uncertainties exist which can be related to the model structure, model parameters and boundary conditions. These inherent uncertainties can be considered in the sensitivity analysis by including them as random input parameters in the LHS. This will result in more insight in the most dominant type of uncertainty, i.e. uncertainty as a result of the input parame- 

Therefore, setting up a sophisticated 2D model for validation will not be needed.

The proposed methodology was tested with the lower-fidelity model predicts a maximum discharge at Lobith of $12,402 \mathrm{~m}^{3} / \mathrm{s}$ for this historic event, deviating only $1.0 \%$ compared to the high-fidelity model $\left(12,282 \mathrm{~m}^{3} / \mathrm{s}\right)$. The uncertainty of this maximum discharge at Lobith equals $49 \mathrm{~m}^{3} / \mathrm{s}$. The uncertainty in model output is relatively small because a large amount of data of the 1926 flood event was ${ }^{1375}$ available. Reconstruction of an older flood event will probably result in larger uncertainties of the input parameters since less information is available. As a result, the truncated normal distributions used to describe the uncertainty of the various input parameters will shift towards uniform distributions. This will have a negative effect on the model output uncertainty.

The sensitivity analysis showed that the model output was most sensitive to the roughness class with the largest share in surface area (in this case the roughness of the grassland areas). Moreover, the location of the roughness class was important since areas close to the river have a relatively large impact on model results. These two aspects in combination with the uncertainty range of the input parameter itself determined the influence on model response.

\section{Acknowledgement}

This research is supported by the Netherlands Organisation for Scientific Research (NWO, project 14506) which is partly funded by the Ministry of Economic Affairs and Climate Policy. Furthermore, the research is supported by the Ministry of Infrastructure and Water Management and Deltares. This research has benefited from cooperation within the network of the Netherlands Centre for River studies NCR (www.ncr-web.org).

The authors would like to thank the Dutch Ministry of Infrastructure and Water Management and the German Federal Institute of Hydrology for providing the data. Besides, the authors would like to thank the following persons for their suggestions and valuable insights: Prof. Dr. Herget (University of Bonn), Dr. Aguilar-Lopez (Technical University Delft), Dr. Lammersen (Dutch Ministry of Infrastructure and Water Management), Van Doornik Msc. (Lievense CSO), Berends Msc. (University of Twente) and Dr. Mara (University of La Réunion). In addition, the authors would like to thank the anonymous reviewer, Sheikholeslami Msc. (Unversity of Saskatchewan) and the associate editor Dr. Razavi for their suggestions during the review process, which greatly improved the quality of the paper.

\section{References}

Barriendos, M., Coeur, D., Lang, M., Llasat, M.C., Naulet, R., Lemaitre, F., Barrera, A., 2003. Stationarity analysis of historical flood series in France and Spain. Natural Hazards and Earth System Sciences 3, 583-592. doi $10.5194 /$ nhess-3-583-2003 
Best, J., 2005. The fluid dynamics of river dunes: A review and some future research directions. Journal of Geophys- 1445 ical Research 110, 1-21. doi 10.1029/2004JF000218

Bladé, E., Gómez-Valentín, M., Dolz, J., Aragón-Hernández, J.L., Corestein, G., Sánchez-Juny, M., 2012. Integration of $1 \mathrm{D}$ and $2 \mathrm{D}$ finite volume schemes for computations of water flow in natural channels. Advances in Water Resources 1450 42, 17-29. doi $10.1016 / \mathrm{j}$.advwatres.2012.03.021

Bomers, A., Schielen, R.M.J., Hulscher, S.J.M.H., 2019. The influence of grid shape and grid size on river modelling performance. Accepted in: Environmental Fluid Mechanics doi 10.1007/s10652-019-09670-4.

Brunner, G.W., 2014. Combined 1D and 2D Modeling with HEC-RAS. Technical Report. Hydrologic Engineering Centre (HEC) of the US Army Crops of Engineers. URL: \{_\}2D \{_\}Modeling \{_\}with\{_\}HEC-RAS.pdf.

Caviedes-Voullième, D., García-navarro, P., Murillo, J., 1460 2012. Influence of mesh structure on $2 \mathrm{D}$ full shallow water equations and SCS Curve Number simulation of rainfall / runoff events. Journal of Hydrology 448, 39-59. doi $10.1016 / \mathrm{j} \cdot \mathrm{jhydrol} .2012 .04 .006$

Book Company, Inc, New York, USA.

Deltares, 2016. D-Flow Flexible Mesh, User Manual. Version 1.2.1. Technical Report. Deltares. Delft.

Der Oberdeichinspektor Dusseldorf, 1895. Deichbuch der Schau Huisberden. Deichfbaue im Niederrhein No. VII.10, 1470 Konigliche Oberdeichinspection Dusseldorf, Book provided by Deichverband Xanten-Kleve.

Dubreuil, S., Berveiller, M., Petitjean, F., Salaün, M., 2014. Construction of bootstrap confidence intervals on sensitivity indices computed by polynomial chaos expansion. 1475 Reliability Engineering and System Safety 121, 263-275. doi $10.1016 /$ j.ress.2013.09.011

Dutch Ministry of Infrastructure and the Environment, 1926. Verslag van het voorgevallene tijdens het hooge opperwater op de Nederlandsche rivieren in den winter 1480 van 1925 op 1926. Technical Report. Ministry of Infrastructure and the Environment. 's-Gravenhage. URL:

https://repository.tudelft.nl/islandora/object/ uuid:5aee4476-3245-42da-a9aa-5807f2b77b6e

1420 Dutch Ministry of Infrastructure and the Environment, 148 1952. Afvoerkrommen 1948-1951 van de Bovenrijn en zijn Takken. Nota 51.23. Technical Report. Rijkswaterstaat, Dir. Bovenrivieren, afd. Studiedienst. Anrhem, the Netherlands.

1425 Dutch Ministry of Infrastructure and the Environment, 1490 Ministry of Economic Affairs, 2014. Delta Programme 2015 - Working on the delta - The decisions to keep the Netherlands safe and liveable. Technical Report. Ministry of Infrastructure and the Environment and

1430 Ministry of Economic Affairs. URL: https://english. 1495

deltacommissaris.nl/delta-programme/documents/ publications/2014/09/16/delta-programme-2015

Efendiev, Y., Datta-Gupta, A., Ginting, V., Ma, X., Mallick, B., 2005. An efficient two-stage Markov chain Monte Carlo method for dynamic data integration. Water Re- 1500 sources Research 41, 1-6. doi 10.1029/2004WR003764

Efron, B., Tibshirani, R.J., 1993. An introduction to the Bootstrap. Chapman \& Hall/CRC, New York, USA. URL: http://projecteuclid.org/euclid.ss/ 1063994971, arXiv:arXiv:1011.1669v3

Gayton, N., Bourinet, J., Lemaire, M., 2003. CQ2RS: a new statistical approach to the response surface method for reliability analysis. Structural Safety 25, 99-121. doi $10.1016 / \mathrm{S} 0167-4730(02) 00045-0$

Herget, J., Kapala, A., Krell, M., Rustemeier, E., Simmer, C., Wyss, A., 2015. The millennium flood of July 1342 revisited. Catena 130, 82-94. doi 10.1016/j.catena. 2014. 12.010

Herget, J., Meurs, H., 2010. Reconstructing peak discharges for historic flood levels in the city of Cologne, Germany. Global and Planetary Change 70, 108-116. doi 10.1016/j.gloplacha.2009.11.011

Horritt, M.S., Bates, P.D., 2002. Evaluation of 1D and 2D numerical models for predicting river flood inundation. Journal of Hydrology 268, 87-99. doi 10.1016/ S0022-1694(02) 00121-X

Janon, A., Nodet, M., Prieur, C., Janon, A., Nodet, M., Prieur, C., 2011. Confidence intervals for sensitivity indices using reduced-basis metamodels. Technical Report. Technical Report, INRIA.

Julien, P.Y., ASCE, M., Klaassen, G.J., Brinke, W.B.M.T., Wilbers, A.W.E., 2002. Case Study: Bed Resistance of Rhine River during 1998 Flood. Journal of Hydraulic Engineering 128. doi 10.1061/(ASCE) /0733-9429(2002)128: 12(1042)

Keating, E.H., Doherty, J., Vrugt, J.A., Kang, Q., 2010. Optimization and uncertainty assessment of strongly nonlinear groundwater models with high parameter dimension-

ality. Water Resources Research 46, 1-18. doi 10.1029/ 2009WR008584

Kernkamp, H.W.J., Van Dam, A., Stelling, G.S., De Goede, E.D., 2011. Efficient scheme for the shallow water equations on unstructured grids with application to the Continental Shelf. Ocean Dynamics 61, 1175-1188. doi 10. 1007/s10236-011-0423-6

Lai, Y.G., 2010. Two-Dimensional Depth-Averaged Flow Modeling with an Unstructured Hybrid Mesh. Journal of Hydraulic Engineering 136, 12-23. doi 10.1061/(ASCE) HY.1943-7900.0000134

Leandro, J., Chen, A.S., Schumann, A., 2014. A 2D parallel diffusive wave model for floodplain inundation with variable time step (P-DWave). Journal of Hydrology 517, 250-259. doi 10.1016/j.jhydrol.2014.05.020

Li, C., Mahadevan, S., 2016. An efficient modularized sample-based method to estimate the first-order Sobol' index. Reliability Engineering and System Safety 153, 110-121. doi 10.1016/j.ress.2016.04.012

Llasat, M.C., Barriendos, M., Barrera, A., Rigo, T., 2005. Floods in Catalonia (NE Spain) since the 14th century. Climatological and meteorological aspects from historical documentary sources and old instrumental records. Journal of Hydrology 313, 32-47. doi $10.1016 / j \cdot j$ hydrol. 2005.02.004.

Maschler, T., Savic, D.a., 1999. Simplification of Water Supply Network Models Through Linearisation. Technical Report. Centre of Water Systems, Report No.99/01, School of Engineering, University of Exeter. Exeter, United kingdom.

McPhee, J., Yeh, W.W.G., 2008. Groundwater Management Using Model Reduction via Empirical Orthogonal Functions. Journal of Water Resources Planning and Management 134, 161-170. doi 10.1061/(ASCE) 0733-9496(2008) 134:2(161)

Moussa, R., Bocquillon, C., 2009. On the use of the diffusive wave for modelling extreme flood events with overbank flow in the floodplain. Journal of Hydrology 374, 116135. doi 10.1016/j.jhydrol.2009.06.006

Moya Quiroga, V., Kure, S., Udo, K., Mano, A., 2016. Ap- 
plication of 2D numerical simulation for the analysis of the February 2014 Bolivian Amazonia flood: Application 1555 of the new HEC-RAS version 5. RIBAGUA - Revista

Iberoamericana del Agua 3, 25-33. doi 10.1016/j.riba. 2015.12.001

Naqshband, S., Ribberink, J.S., Hulscher, S.J.M.H., 2014. Using Both Free Surface Effect and Sediment Trans- 1560 port Mode Parameters in Defining the Morphology of River Dunes and Their Evolution to Upper Stage Plane

neds. Journal of Hydraulic Engineering 140. doi 10.1061/ (ASCE) HY.1943-7900.0000873

Neppel, L., Renard, B., Lang, M., Ayral, P.a., Coeur, D., 1565 Gaume, E., Jacob, N., Payrastre, O., Pobanz, K., Vinet, F., 2010. Flood frequency analysis using historical data: accounting for random and systematic errors and systematic errors. Hydrological Sciences Journal 55, 192-208. doi $10.1080 / 02626660903546092$

O'Connell, D.R.H., Ostenaa, D.A., Levish, D.R., Klinger, R.E., 2002. Bayesian flood frequency analysis with paleohydrologic bound data. Water Resources Research 38, 1058-1071. doi 10.1029/200WR000028

Paarlberg, A.J., Dohmen-janssen, C.M., Hulscher, S.J.M.H., 1575 Termes, P., Schielen, R., 2010. Modelling the effect of time-dependent river dune evolution on bed roughness and stage. Earth surface processes and landforms doi 10.1002/esp.2074.

1535 Pappenberger, F., Beven, K., Horritt, M., Blazkova, S., 1580 2005. Uncertainty in the calibration of effective roughness parameters in HEC-RAS using inundation and downstream level observations. Journal of Hydrology 302, 4669. doi 10.1016/j j jhydrol.2004.06.036

Razavi, S., Tolson, B.A., Burn, D.H., 2012a. Numer- 1585 ical assessment of metamodelling strategies in computationally intensive optimization. Environmental Modelling and Software 34, 67-86. URL: http://dx.

doi.org/10.1016/j.envsoft.2011.09.010 doi 10.1016/ j.envsoft.2011.09.010

Razavi, S., Tolson, B.A., Burn, D.H., 2012b. Review of surrogate modeling in water resources. Water Resources Research 48. doi 10.1029/2011WR011527

Saltelli, A., Chan, K., Scott, E.M., 2000. Sensitivity Analysis. John Wiley \& Sons, Ltd.

Saltelli, A., Ratto, M., Andres, T., Campologno, F., Cariboni, J., Gatelli, D., Saisana, M., Tarantola, S., 2008. Global Sensitivity Analysis: The Primer. John Wiley \&
Sons, Ltd

Scheidt, C., Li, L., Caers, J., 2018. Quantifying Uncertainty in Subsurface Systems. Volume 236 of Geophysical Monograph Series. John Wiley \& Sons, Ltd.

Sheffer, N.A., Enzel, Y., Benito, G., Grodek, T., Poart, N., Lang, M., Naulet, R., Cour, D., 2003. Paleofloods and historical floods of the Ardeche River, France. Water Resources Research 39. doi 10.1029/2003WR002468

Silva, W., Klijn, F., Dijkman, J., 2001. Room for the Rhine Branches in The Netherlands. What the research has taught us. Technical Report. WL — Delft Haydraulics report R3294. Delft, The Netherlands.

Simpson, T.W., Peplinski, J., Koch, P.N., Allen, J.K., 2001. Metamodels for computer-based engineering design: Survey and recommendations. Engineering with Computers 17, 129-150. doi 10.1007/PL00007198

570 Tayefi, V., Lane, S.N., Hardy, R.J., Yu, D., 2007. A comparison of one- and two-dimensional approaches to modelling flood inundation over complex upland floodplains. Hydrological processes 21, 3190-3202. doi 10.1002/hyp.6523

The OpenDA Association, 2016. OpenDA User Documentation. Technical Report. URL: info@openda.org.

Thokala, P., Martins, J.R., 2007. Variable-complexity optimization applied to airfoil design. Engineering Optimization 39, 271-286. doi 10.1080/03052150601107976

Toonen, W.H.J., Winkels, T.G., Cohen, K.M., Prins, M.A., Middelkoop, H., 2015. Lower Rhine historical flood magnitudes of the last 450 years reproduced from grain-size measurements of flood deposits using End Member Mod-

n elling. Catena 130, 69-81. doi 10.1016/j.catena.2014. 12.004

Ulanicki, B., Zehnpfund, A., Martinez, F., 1996. Simplification of Water Distribution Network Models, in: Proceedings of the 2nd International Conference on Hydroinformatics, Rotterdam, The Netherlands. pp. 493-500. doi $10.13140 /$ RG.2.1.4340.8404

Warmink, J.J., Straatsma, M.W., Huthoff, F., Booij, M.J., Hulscher, S.J., 2013. Uncertainty of design water levels due to combined bed form and vegetation roughness in the Dutch River Waal. Journal of Flood Risk Management 6, 302-318. doi 10.1111/jfr3.12014

Zhou, Y., Ma, Z., Wang, L., 2002. Chaotic dynamics of the flood series in the Huaihe River Basin for the last 500 years. Journal of Hydraulic Engineering 258, 100-110. doi 10.1016/S0022-1694(01) 00561-3 